Journal of Engineering and Applied Sciences 14 (22): 8147-8159, 2019

ISSN: 1816-949X

(C) Medwell Journals, 2019

\title{
Estimating Reliability and Availability Function for Different Production Systems
}

\author{
Haidar A. Ameer \\ Department of Business Administration, Albayan University, Baghdad, Iraq
}

\begin{abstract}
This study introduces a new generalization of the transmuted Marshall-Olkin Frechet distribution of Afify using Kumaraswamy generalized family. The new model is referred to as Kumaraswamy transmuted Marshall-Olkin Frechet distribution. This model contains 62 sub-models as special cases such as the Kumaraswamy transmuted Frechet, Kumaraswamy transmuted Marshall-Olkin, generalized inverse Weibull and Kumaraswamy Gumbel type 2 distributions among others. Various mathematical properties of the proposed distribution including closed forms for ordinary and incomplete moments, quantile and generating functions and Renyi and $\eta$-entropies are derived. The unknown parameters of the new distribution are estimated using the maximum likelihood estimation. We illustrate the importance of the new model by means of two applications to real data sets.
\end{abstract}

Key words: Moments of residual life, goodness of fit order statistics, maximum likelihood estimation, model, generating functions, Gumbel type 2

\section{INTRODUCTION}

The procedure of expanding a family of distributions for added flexibility or to construct covariate models is a well-known technique in the literature. In many applied sciences such as medicine, engineering and finance amongst others, modeling and analyzing lifetime data are crucial. Several lifetime distributions have been used to model such kinds of data. The quality of the procedures used in a statistical analysis depends heavily on the assumed probability model or distributions. Because of this, considerable effort has been expended in the development of large classes of standard probability distributions along with relevant statistical methodologies. However, there still remain many important problems where the real data does not follow any of the classical or standard probability models. The Frechet distribution is one of the important distributions in extreme value theory and it has been applied to data on characteristics of sea waves and wind speeds. Further information about the Frechet distribution and its applications were discussed by Kotz and Nadarajah (2000).

Recently, some extensions of the Frechet distribution are considered. The exponentiated Frechet (Kotz and Nadarajah, 2000), beta Frechet (Nadarajah and Gupta, 2004; Barreto-Souza et al., 2011), transmuted Frechet (Mahmoud and Mandouh, 2013), Marshall-Olkin Frechet (Krishna et al., 2013), gamma extended Frechet (Da Silva et al., 2013), transmuted exponentiated Frechet (Elbatal et al., 2014), Kumaraswamy Frechet (Mead, 2014), Transmuted Marshall-Olkin Frechet (TMOF) (Afify et al., 2014a, b), transmuted exponentiated generalized Frechet (Yousof et al., 2015), beta exponential Frechet (Mead et al., 2017) and Weibull Frechet (Afify et al., $2016 \mathrm{a}$, b) distributions. The cumulative distribution function (cdf) of the TMOF distribution is given (for $\mathrm{x}>0$ ) by:

$$
\mathrm{F}(\mathrm{x})=\frac{\alpha(1+\lambda) \exp \left[-\left(\frac{\theta}{\mathrm{x}}\right)^{\beta}\right]-(\alpha \lambda+\alpha-1) \exp \left[-2\left(\frac{\theta}{\mathrm{x}}\right)^{\beta}\right]}{\left\{\alpha+(1-\alpha) \exp \left[-\left(\frac{\theta}{\mathrm{x}}\right)^{\beta}\right]\right\}^{2}}(1)
$$

Where:

$\alpha, \beta$ and $\theta=$ The positive

$|\lambda| \leq 1,0 \quad=$ A scale parameter

$\alpha, \beta$ and $\lambda=$ Shape parameters

The corresponding probability density function (pdf) is given by:

$$
f(x)=\frac{\frac{\alpha \beta}{\theta}\left(\frac{\theta}{x}\right)^{\beta+1} \exp \left[-\left(\frac{\theta}{x}\right)^{\beta}\right]\left[\begin{array}{c}
\alpha(1+\lambda)-(\alpha \lambda+\alpha+\lambda-1) \\
\exp \left[-\left(\frac{\theta}{x}\right)^{\beta}\right]
\end{array}\right\}}{\left\{\alpha+(1-\alpha) \exp \left[-\left(\frac{\theta}{x}\right)^{\beta}\right]\right\}^{3}}
$$

In this study, we present a new generalization of the TMOF distribution called Kumaraswamy transmuted Marshall-Olkin Frechet (Kw-TMOF) distribution based on the family of Kumaraswamy generalized (Kw-G) distributions introduced by 
Cordeiro and de Castro (2011). The main motivation for this extension is that the new distribution is a highly flexible life distribution which contains as sub models 62 well known and unknown distributions, admits different degrees of kurtosis and asymmetry and the Kumaraswamy transmuted Marshall-Olkin Frechet (Kw-TMOF) distribution provides a superior fit to real data than its sub models and non-nested models.

\section{MATERIALS AND METHODS}

Definition 1: A random variable $X$ is said to have $\mathrm{Kw}-\mathrm{G}$ distribution if its cdf is given by:

$$
F(x)=1-\left[1-G(x)^{a}\right]^{b}
$$

where, $a>0$ and $b>0$ are 2 additional parameters whose role is to introduce skewness and to vary tail weights. The corresponding pdf is given by:

$$
f(x)=\operatorname{abg}(x) G(x)^{a-1}\left[1-G(x)^{a}\right]^{b-1}
$$

where, $\mathrm{G}(\mathrm{x})$ and $\mathrm{g}(\mathrm{x})$ are the cdf and pdf of the baseline distribution, respectively. Clearly when $a=b=1$, we obtain the baseline distribution.

Providing a new class of distributions is always precious for statisticians. Thus, the aim of this study is to study the Kw-TMOF distribution. The fact that the $\mathrm{Kw}-\mathrm{TMOF}$ distribution generalizes existing commonly used distributions and introduces new lifetime models is an important aspect of the model. Further, we demonstrate that the proposed model provides a significant improvement compared to some existing lifetime models and it is also a competitive model to the gamma extended Frechet (Da Silva et al., 2013) and beta Frechet (Barreto-Souza et al., 2011) distributions. In addition, we investigate some mathematical properties of the new model, discuss maximum likelihood estimation of its parameters and derive the observed information matrix.

The rest of the study is outlined as follows. In this study, we demonstrate the subject distribution and the expantions for the pdf and cdf. The statistical properties include quantile functions, random number generation, moments, moment generating functions incomplete moments, mean deviations and Renyi and $\eta$-entropies are derived in this stusy. The order statistics and their moments are investigated in study. The characterization of the $\mathrm{Kw}-\mathrm{TMOF}$ in terms of a truncated moment of a function of the random variable is given in this study. In this study, we discuss maximum likelihood estimation of the model parameters. In this study, the $\mathrm{Kw}-\mathrm{TMOF}$ distribution is applied to two real data sets to illustrate the potentiality of the new distribution for lifetime data modeling. Finally, we provide some concluding remarks in this study.

Significance of study: The researcch demonstrate that the proposed model provides a significant improvement compared to some existing lifetime models and it is also a competitive model to the gamma extended Frechet (Da Silva et al., 2013) and beta Frechet (Barreto-Souza et al., 2011) distributions. In addition, we investigate some mathematical properties of the new model, discuss maximum likelihood estimation of its parameters and derive the observed information matrix.

The Kw-TMOF distribution: The $\mathrm{Kw}$-TMOF distribution and its sub-models are presented in this study. A random variable $\mathrm{X}$ is said to have $\mathrm{Kw}-\mathrm{TMOF}$ with vector parameters $\phi$ where $(\alpha, \beta, \theta, \lambda, \mathrm{a}, \mathrm{b})$, if its cdf is defined (for $\mathrm{x}>0$ ) by:

$$
\mathrm{F}(\mathrm{x}, \phi)=1-\left\{\begin{array}{c}
-\left[\alpha(1+\lambda) \mathrm{e}^{-\left(\frac{\theta}{\mathrm{x}}\right)^{\beta}}-(\alpha \lambda+\alpha-1) \mathrm{e}^{-2\left(\frac{\theta}{\mathrm{x}}\right)^{\beta}}\right]^{\alpha} \\
{\left[\alpha+(1-\alpha) \mathrm{e}^{-\left(\frac{\theta}{\mathrm{x}}\right)^{\beta}}\right]^{-2 a}}
\end{array}\right\}^{b}
$$

where, a, b are 2 additional shape parameters. The corresponding pdf of the $\mathrm{Kw}-\mathrm{TMOF}$ is given by:

$$
\begin{aligned}
& f(x, j)=a b \alpha \beta \theta^{\beta} x^{-\beta-1} \frac{\alpha(1+\lambda) e^{-\left(\frac{\theta}{x}\right)^{\beta}}-(\alpha \lambda+\alpha+\lambda-1) e^{-2\left(\frac{\theta}{x}\right)^{\beta}}}{\left[\alpha+(1-\alpha) e^{-\left(\frac{\theta}{x}\right)^{\beta}}\right]^{2 a+1}} \times
\end{aligned}
$$

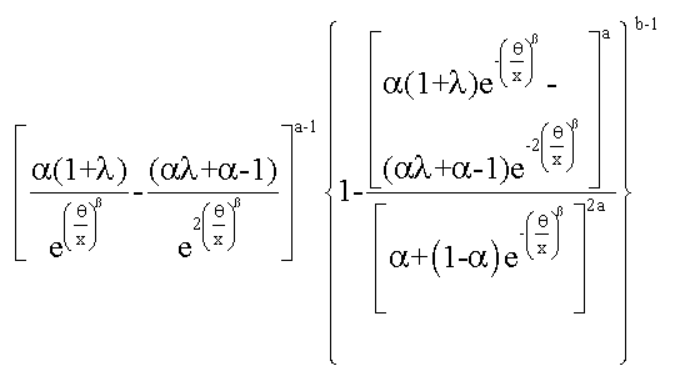

A physical interpretation of Eq. 4 is possible when a and $b$ are positive integers. Suppose a system is made up of $\mathrm{b}$ independent components in series and that each component is made up of a independent subcomponents in parallel. So, the system fails if any of the $b$ 
components fail and each component fails if all of its a subcomponents fail. If the sub-component lifetimes have a common $\mathrm{Kw}$-TMOF cumulative function, then the lifetime of the entire system will follow the Kw-TMOF distribution (Eq. 4).

From another view, suppose a system consists of b independent sub-systems functioning independently at a given time and that each sub-system consists of a independent parallel components. Suppose too that each component consists of two units. If the two units are connected in series then the overall system will have $\mathrm{Kw}$-TMOF distribution with $\lambda=1$ whereas if the components are parallel then the overall system will have $\mathrm{Kw}$-TMOF distribution with $\lambda=-1$.

Furthermore, we can interpret the system from the redundancy view. Redundancy is a common method to increase reliability in an engineering design. Barlow and Proschan (1996) indicate that, if we want to increase the reliable of a given system, then redundancy at a component level is more effective than redundancy at a system level. That is, if all components of a system are available in duplicate, it is better to put these component pairs in parallel than it is to build two identical systems and place the systems in parallel.

The proposed $\mathrm{Kw}$-TMOF Model is very flexible model that approaches to different distributions when its parameters are changed. The flexibility of the $\mathrm{Kw}-\mathrm{TMOF}$ is explained in Table 1 where it has 62 sub-models when their parameters are carefully chosen. The reliability function (rf), hazard rate function (hrf) and cumulative hazard rate function (chrf) are respectively, given by:

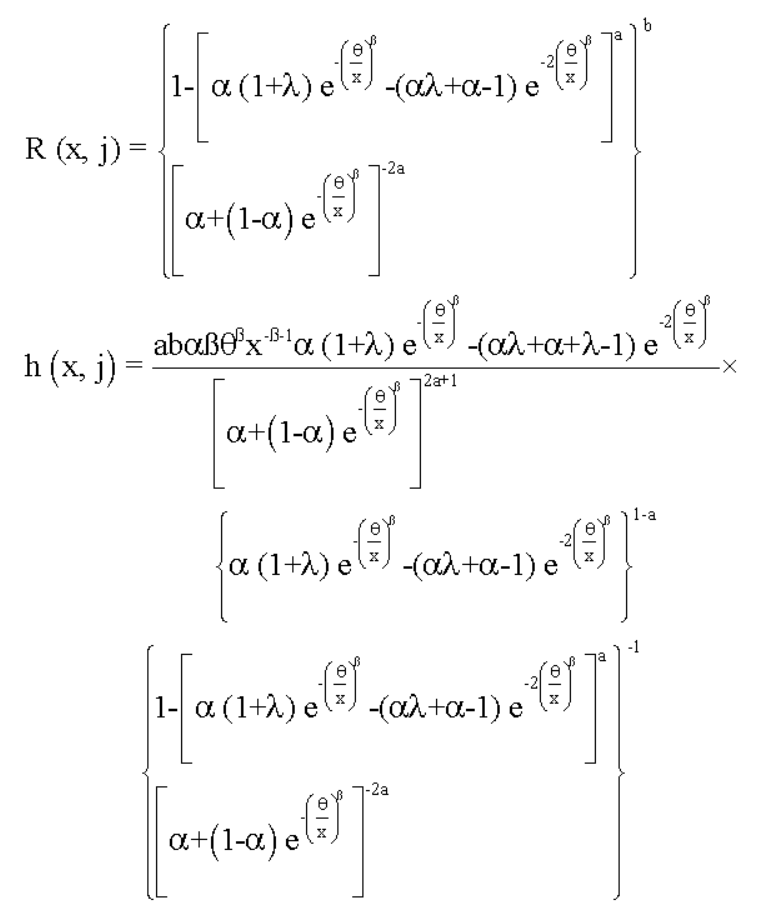

and:

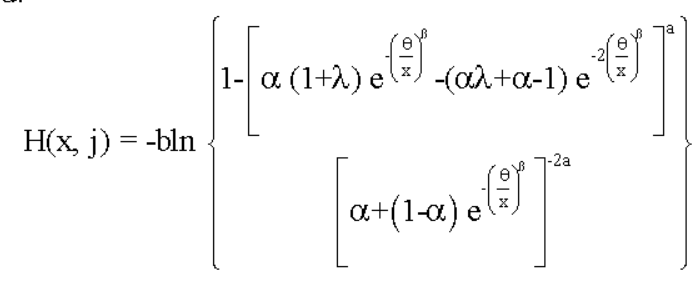

Figure 1 provides the some plots of the $\mathrm{Kw}-\mathrm{TMOF}$ density curves for different values of the

Table 1: Sub-models of the Kw-TMOF distribution

\begin{tabular}{llllllll} 
Distribution & $\alpha$ & $\beta$ & $\theta$ & $\lambda$ & $\mathrm{a}$ & $\mathrm{b}$ & Researchers \\
\hline KTF & 1 & $\beta$ & $\theta$ & $\lambda$ & $\mathrm{a}$ & $\mathrm{b}$ & New \\
KTMOIE & $\alpha$ & 1 & $\theta$ & $\lambda$ & $\mathrm{a}$ & $\mathrm{b}$ & New \\
KTMOIR & $\alpha$ & 2 & $\theta$ & $\lambda$ & $\mathrm{a}$ & $\mathrm{b}$ & New \\
KTMOGIW & $\alpha$ & $\beta$ & $\mathrm{qc}^{1 / \beta}$ & $\lambda$ & $\mathrm{a}$ & $\mathrm{b}$ & New \\
KTMOGuI & $\alpha$ & $\beta$ & $\mathrm{p}=\theta^{\beta}$ & $\lambda$ & $\mathrm{a}$ & $\mathrm{b}$ & New \\
KTMOIW & $\alpha$ & $\beta$ & $\mathrm{c}^{1 / \beta}$ & $\lambda$ & $\mathrm{a}$ & $\mathrm{b}$ & New \\
KTGIW & 1 & $\beta$ & $\mathrm{qc}^{1 / \beta}$ & $\lambda$ & $\mathrm{a}$ & $\mathrm{b}$ & New \\
KTGuII & 1 & $\beta$ & $\mathrm{p}=\theta^{\beta}$ & $\lambda$ & $\mathrm{a}$ & $\mathrm{b}$ & New \\
KTIW & 1 & $\beta$ & $\mathrm{c}^{1 / \beta}$ & $\lambda$ & $\mathrm{a}$ & $\mathrm{b}$ & New \\
KTIE & 1 & 1 & $\theta$ & $\lambda$ & $\mathrm{a}$ & $\mathrm{b}$ & New \\
KTIR & 1 & 2 & $\theta$ & $\lambda$ & $\mathrm{a}$ & $\mathrm{b}$ & Mead (2014) \\
KF & 1 & $\beta$ & $\theta$ & 0 & $\mathrm{a}$ & $\mathrm{b}$ & Afify et al. (2016a, b) \\
KMOF & $\alpha$ & $\beta$ & $\theta$ & 0 & $\mathrm{a}$ & $\mathrm{b}$ & - \\
KMOIE & $\alpha$ & 1 & $\theta$ & 0 & $\mathrm{a}$ & $\mathrm{b}$ & - \\
KMOIR & $\alpha$ & 2 & $\theta$ & 0 & $\mathrm{a}$ & $\mathrm{b}$ & New \\
KMOGIW & $\alpha$ & $\beta$ & $\mathrm{qc}$ & 0 & $\mathrm{a}$ & $\mathrm{b}$ & New \\
KMOGuII & $\alpha$ & $\beta$ & $\mathrm{p}=\theta^{1 / \beta}$ & 0 & $\mathrm{a}$ & $\mathrm{b}$ & New \\
KMOIW & $\alpha$ & $\beta$ & $\mathrm{c}^{1 / \beta}$ & 0 & $\mathrm{a}$ & $\mathrm{b}$ & Afify et al. (2016a, b) \\
KGIW & 1 & $\beta$ & $\mathrm{q} \mathrm{c}^{1 / \beta}$ & 0 & $\mathrm{a}$ & $\mathrm{b}$ & Afify et al. (2016a, b) \\
KGuII & 1 & $\beta$ & $\mathrm{p}=\theta^{\beta}$ & 0 & $\mathrm{a}$ & $\mathrm{b}$ & Shahbaz et al. (2012) \\
KIW & 1 & $\beta$ & $\mathrm{c}^{1 / \beta}$ & 0 & $\mathrm{a}$ & $\mathrm{b}$ & Mead (2014) \\
KIE & 1 & 1 & $\theta$ & 0 & $\mathrm{a}$ & $\mathrm{b}$ & Mead (2014) \\
KIR & 1 & 2 & $\theta$ & 0 & $\mathrm{a}$ & $\mathrm{b}$ & \\
\hline
\end{tabular}




\begin{tabular}{|c|c|c|c|c|c|c|c|}
\hline Distribution & $\alpha$ & $\beta$ & $\theta$ & $\lambda$ & $\mathrm{a}$ & $\mathrm{b}$ & Researchers \\
\hline TMOF & $\alpha$ & $\beta$ & $\theta$ & $\lambda$ & 1 & 1 & Afify et al. $(2014 a, b)$ \\
\hline TMOIE & $\alpha$ & 1 & $\theta$ & $\lambda$ & 1 & 1 & -- \\
\hline TMOIR & $\alpha$ & 2 & $\theta$ & $\lambda$ & 1 & 1 & -- \\
\hline TMOGIW & $\alpha$ & $\beta$ & $\mathrm{qc}^{1 / \beta}$ & $\lambda$ & 1 & 1 & New \\
\hline TMOGuII & $\alpha$ & $\beta$ & $\mathrm{p}=\theta^{\beta}$ & $\lambda$ & 1 & 1 & New \\
\hline TMOIW & $\alpha$ & $\beta$ & $c^{1 / \beta}$ & $\lambda$ & 1 & 1 & New \\
\hline TEGIW & 1 & $\beta$ & $\mathrm{qc}^{1 / \beta}$ & $\lambda$ & 1 & $\mathrm{~b}$ & New \\
\hline TEGuII & 1 & $\beta$ & $\mathrm{p}=\theta^{\beta}$ & $\lambda$ & 1 & $\mathrm{~b}$ & New \\
\hline TEIW & 1 & $\beta$ & $c^{1 / \beta}$ & $\lambda$ & 1 & $\mathrm{~b}$ & New \\
\hline TGIW & 1 & $\beta$ & $\mathrm{qc}^{1 / \beta}$ & $\lambda$ & 1 & 1 & Merovci et al. (2013) \\
\hline Tgull & 1 & $\beta$ & $\mathrm{p}=\theta^{\beta}$ & $\lambda$ & 1 & 1 & New \\
\hline TIW & 1 & $\beta$ & $c^{1 / \beta}$ & $\lambda$ & 1 & 1 & Khan et al. (2013) \\
\hline MOFD & $\alpha$ & $\beta$ & $\theta$ & 0 & 1 & 1 & Krishna et al. (2013) \\
\hline MOIE & $\alpha$ & 1 & $\theta$ & 0 & 1 & 1 & -- - y - y \\
\hline MOIR & $\alpha$ & 2 & $\theta$ & 0 & 1 & 1 & -- \\
\hline MOGIW & $\alpha$ & $\beta$ & $\mathrm{qc}^{1 / \beta}$ & 0 & 1 & 1 & New \\
\hline MOGuII & $\alpha$ & $\beta$ & $\mathrm{p}=\theta^{\beta}$ & 0 & 1 & 1 & New \\
\hline MOIW & $\alpha$ & $\beta$ & $c^{1 / \beta}$ & 0 & 1 & 1 & New \\
\hline TEF & 1 & $\beta$ & $\theta$ & $\lambda$ & 1 & $\mathrm{~b}$ & Elbatal et al. (2014) \\
\hline TEIE & 1 & 1 & $\theta$ & $\lambda$ & 1 & $\mathrm{~b}$ & -- \\
\hline TEIR & 1 & 2 & $\theta$ & $\lambda$ & 1 & $\mathrm{~b}$ & -- \\
\hline TF & 1 & $\beta$ & $\theta$ & $\lambda$ & 1 & 1 & Mahmoud and Mandouh (2013) \\
\hline TIE & 1 & 1 & $\theta$ & $\lambda$ & 1 & 1 & Oguntunde and Adejumo (2015) \\
\hline TIR & 1 & 2 & $\theta$ & $\lambda$ & 1 & 1 & Ahmad et al. (2014) \\
\hline $\mathrm{EF}$ & 1 & $\beta$ & $\theta$ & 0 & 1 & $\mathrm{~b}$ & Kotz and Nadarajah (2000) \\
\hline EIE & 1 & 1 & $\theta$ & 0 & 1 & $\mathrm{~b}$ & -- \\
\hline EIR & 1 & 2 & $\theta$ & 0 & 1 & $\mathrm{~b}$ & -- \\
\hline TGF & 1 & $\beta$ & $\theta$ & $\lambda$ & a & 1 & New \\
\hline TGIE & 1 & 1 & $\theta$ & $\lambda$ & $\mathrm{a}$ & 1 & New \\
\hline TGIR & 1 & 2 & $\theta$ & $\lambda$ & a & 1 & New \\
\hline GF & 1 & $\beta$ & $\theta$ & 0 & $\mathrm{a}$ & 1 & New \\
\hline GIE & 1 & 1 & $\theta$ & 0 & $\mathrm{a}$ & 1 & New \\
\hline GIR & 1 & 2 & $\theta$ & 0 & $\mathrm{a}$ & 1 & New \\
\hline GIW & 1 & $\beta$ & $\mathrm{qc}^{1 / \beta}$ & 0 & 1 & 1 & De Gusmao et al. (2011) \\
\hline GuII & 1 & $\beta$ & $\mathrm{p}=\theta^{\beta}$ & 0 & 1 & 1 & Gumbel (1958) \\
\hline IW & 1 & $\beta$ & $c^{1 / \beta}$ & 0 & 1 & 1 & Keller et al. (1982) \\
\hline $\mathrm{F}$ & 1 & $\beta$ & $\theta$ & 0 & 1 & 1 & Frechet (1924) \\
\hline IE & 1 & 1 & $\theta$ & 0 & 1 & 1 & Keller et al. (1982) \\
\hline IR & 1 & 2 & $\theta$ & 0 & 1 & 1 & Treyer (1964) \\
\hline
\end{tabular}

parameters $\alpha, \beta, \theta, \lambda, \quad a$ and $b$. Some plots of the hrf of the Kw-TMOF are displayed in Fig. 2.

Useful expansions: Expansions for Eq. 3 and 4 can be derived using using the series expansion:

$$
(1-z)^{k}=\sum_{j=0}^{\infty} \frac{(-1)^{j} \Gamma(k+1)}{j ! \Gamma(k-j+1)} z^{j},|z|<1, k>0
$$

The cdf of the Kw-TMOF in Eq. 3 can be expressed in the mixture form:

$$
F(x, \phi)=1-\sum_{j, i, k=0}^{\infty} s_{j, i k} \exp \left[-(a j+k+i)\left(\frac{\theta}{x}\right)^{\beta}\right]
$$

where:

$$
\begin{aligned}
& (-1)^{j+i} \Gamma(b+1) \Gamma(a j+1) \Gamma \\
& \mathrm{s}_{\mathrm{j}, \mathrm{i.k}}=\frac{(2 \mathrm{aj}+\mathrm{k})(\alpha \lambda+\alpha-1)^{\mathrm{i}}}{\mathrm{j} ! \mathrm{i} ! \mathrm{k} ! \alpha^{2 \mathrm{i} i} \Gamma(2 \mathrm{aj}) \Gamma(\mathrm{b}-\mathrm{j}+1) \Gamma}\left(1-\frac{1}{\alpha}\right)^{\mathrm{k}} \\
& (a \mathrm{j}-\mathrm{i}+1)(\alpha \lambda+\alpha)^{-\mathrm{aj}+\mathrm{i}}
\end{aligned}
$$

The pdf of the Kw-TMOF in Eq. 4 can be expressed in the mixture form:

$$
\begin{aligned}
& f(x, \phi)=\beta \theta^{\beta} x^{-(\beta+1)} \\
& \sum_{j, i, k, w=0}^{\infty} b_{j, i, k, w} \exp \left[-(a j+a+i+k+w)\left(\frac{\theta}{x}\right)^{\beta}\right]
\end{aligned}
$$

where:

$$
\begin{gathered}
\mathrm{ab}(-1)^{j+i+w} \Gamma(\mathrm{b}) \Gamma(\mathrm{aj}+\mathrm{a}) \Gamma \\
\mathrm{b}_{\mathrm{j}, \mathrm{i}, \mathrm{k}, \mathrm{w}}=\frac{(2 \mathrm{aj}+2 \mathrm{a}+\mathrm{k}+1)\left(1-\frac{1}{\alpha}\right)^{\mathrm{k}}(\alpha \lambda+\alpha)^{\mathrm{a}(\mathrm{j}+1)-\mathrm{i}-\mathrm{w}}}{\mathrm{j} ! \mathrm{i} ! \mathrm{k} ! \mathrm{w} ! \Gamma(\mathrm{b}-\mathrm{j}) \Gamma(\mathrm{aj}+\mathrm{a}-\mathrm{i}) \Gamma(2 \mathrm{aj}+2 \mathrm{a}+1) \Gamma} \\
(2-\mathrm{w}) \alpha^{2 \mathrm{a}(j+1)}(\alpha \lambda+\alpha-1)^{\mathrm{i}}(\alpha \lambda+\alpha+\lambda-1)^{-\mathrm{w}}
\end{gathered}
$$

The Kw-TMOF density function can be expressed as a mixture of Fréchet densities. Thus, some of its mathematical properties can be obtained directly from those properties of the Frechet distribution. Therefore, Eq. 4 can be also expressed as: 


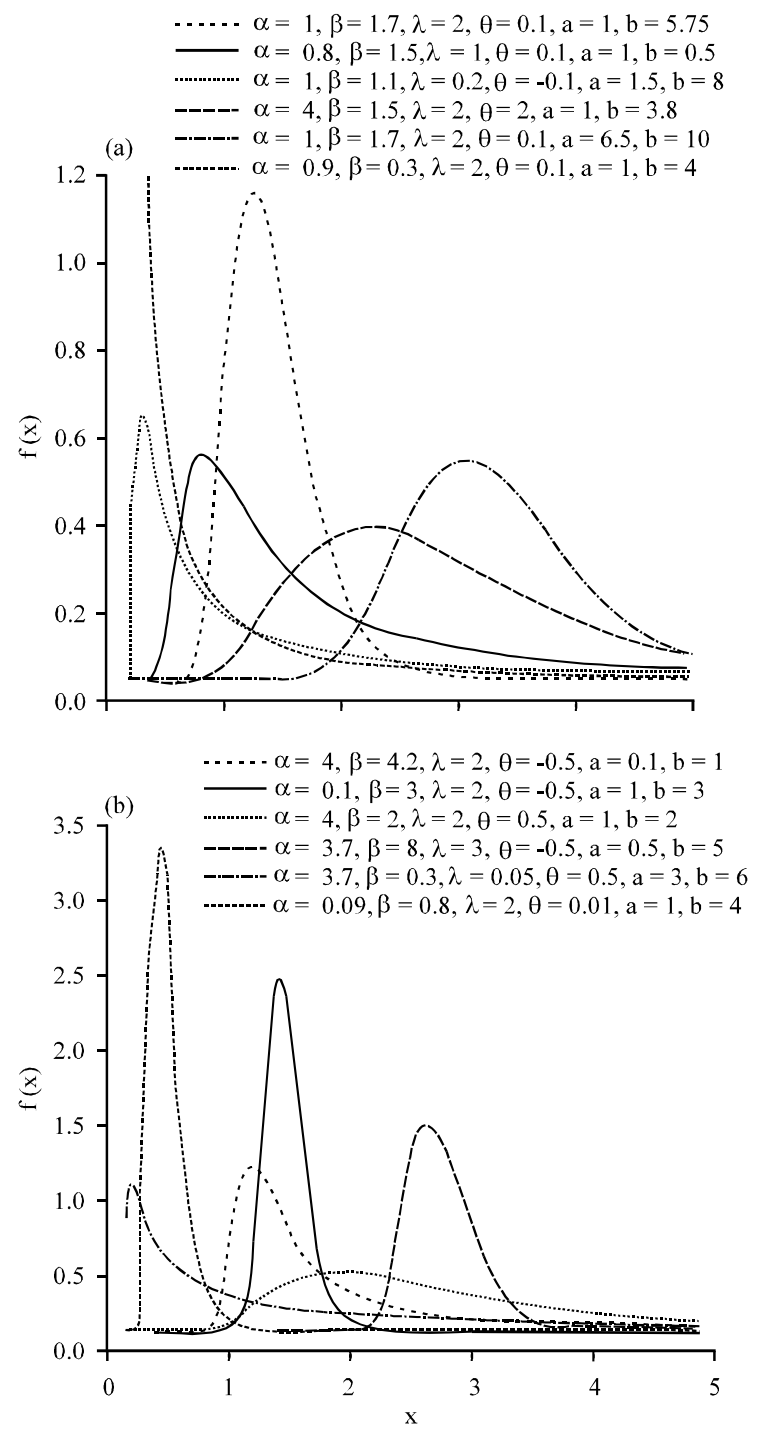

Fig. 1: a, b) Plots of the Kw-TMOF density function for some parameter values

$$
f(x, \phi)=\sum_{j, i, k, w=0}^{\infty} \frac{b_{j, i, k, w}}{(a j+a+i+k+w)} g\left(x ; \beta, \theta^{*}\right)
$$

where, $g\left(x ; \beta, \theta^{*}\right)$ denotes to the Frechet pdf where $\theta^{*}=$ $\theta(a j+a+i+k+w)^{1 / \beta}$.

\section{Properties}

Quantile function: The quantile function (qf) of is obtained by inverting (Eq. 3) as:

$$
Q(u)=\theta\left\{\ln \left(\frac{\kappa+\sqrt{\alpha^{2}\left(\lambda^{2}+2 \lambda+1\right)-4 \alpha^{2} \lambda \sqrt[2]{1-\sqrt[b]{1-u}}}}{2 \alpha^{2} \sqrt[2]{1-\sqrt[b]{1-u}}}\right)\right\}^{-1 / 3}, 0 \leq u \leq 1
$$

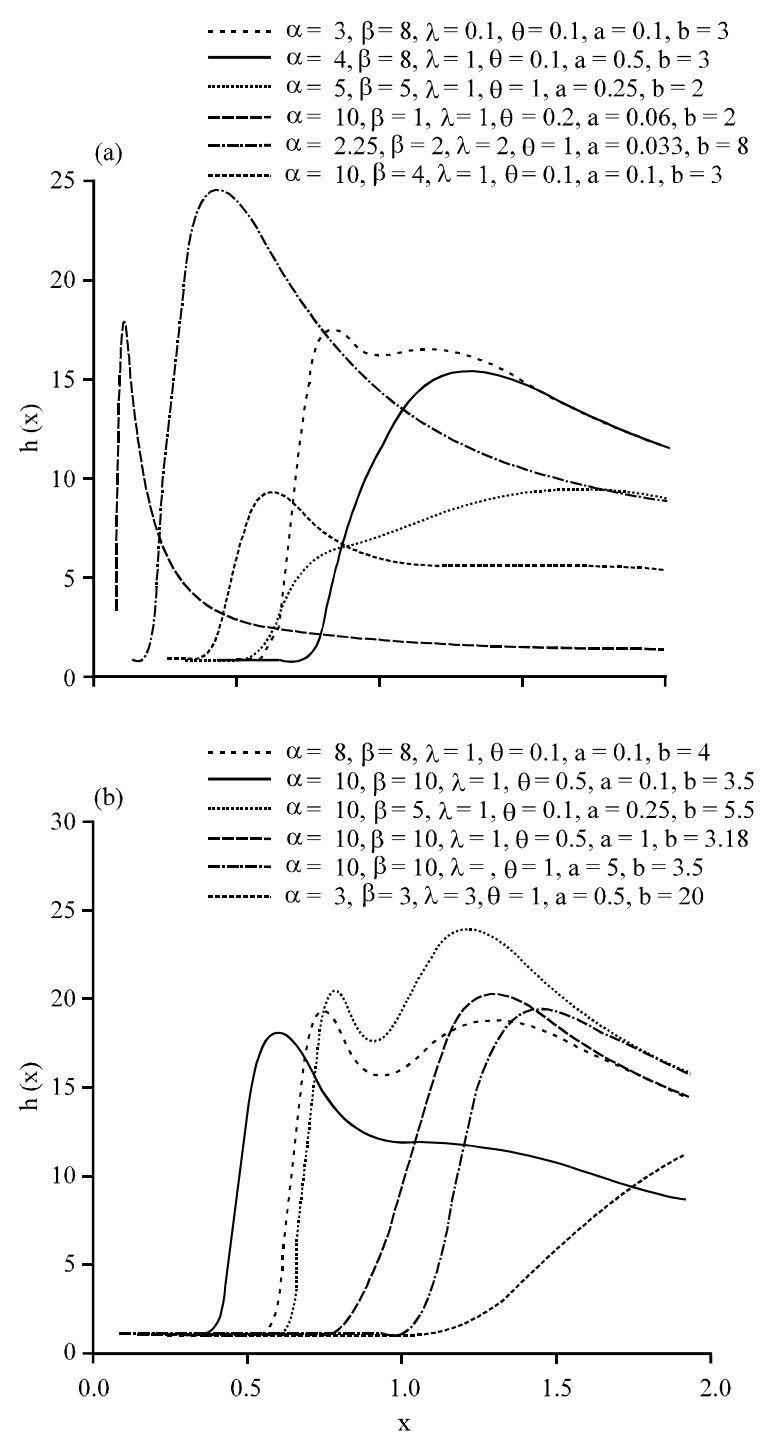

Fig. 2: a, b) Plots of the Kw-TMOF hrf

where, $k=\alpha(\lambda+1)-2 \alpha(1-\alpha) \sqrt[2]{1-\sqrt{1-u}}$.

Simulating the $\mathrm{Kw}-\mathrm{TMOF}$ random variable is straightforward. If $U$ is a uniform variate on the unit interval $(0,1)$ then the random variable $\mathrm{X}=$ $\mathrm{Q}(\mathrm{U})$ follows Eq. 4, i.e., X: Kw-TMOF $(\alpha, \beta, \theta$, $\lambda, a, b)$

Ordinary and incomplete moments: The rth moment, denoted by $\mu_{r}^{\prime}$ of $X$ (for $r<\beta$ ) is given as by:

$$
\mu_{r}^{\prime}=E\left(X^{r}\right)=\frac{\theta^{r} \sum_{j, i, k, w=0}^{\infty} b_{j, i, k, w}}{(a j+a+i+k+w)^{1 \cdot(t / \beta)}} \Gamma\left(1-\frac{r}{\beta}\right)
$$


Sitting $r=1$, we get the mean of $X$. The skewness and kurtosis measures can be calculated from the ordinary moments using well-known relationships.

Corollary 1: Using the relation between the central moments and non-centeral moments, we can obtain the nth central moment, denoted by $\mathrm{M}_{\mathrm{n}}$, of a $\mathrm{Kw}-\mathrm{TMOF}$ random variable as follows:

$$
M_{n}=E(X-\mu)^{n}=\sum_{r=0}^{\infty}\left(\begin{array}{l}
n \\
r
\end{array}\right)(-\mu)^{n-r} E\left(X^{r}\right)
$$

where, $\mathrm{E}\left(\mathrm{X}^{\mathrm{r}}\right)$ is the on-central moments of the Kw-TMOF $(\alpha, \beta, \theta, a, b, x)$. Therefore, the $n$th central moments of the $\mathrm{Kw}-\mathrm{TMOF}(\alpha, \beta, \theta, \mathrm{a}, \mathrm{b}, \mathrm{x})$ if $\mathrm{r}<\beta$ is given by:

$$
M_{n}=\sum_{r=0}^{\infty}\left(\begin{array}{l}
n \\
r
\end{array}\right)(-\mu)^{n-r} \frac{\theta^{r} \sum_{j=0}^{\infty} b_{j, i, k, w}}{(a j+a+i+k+w)^{1-(r / \beta)}} \Gamma\left(1-\frac{r}{\beta}\right)
$$

The moment generating function (mgf) of X say $\mathrm{M}_{\mathrm{X}}$ $(\mathrm{t})=\mathrm{E}\left(\mathrm{e}^{\mathrm{tx}}\right),($ for $\mathrm{r}<\beta)$ is given by:

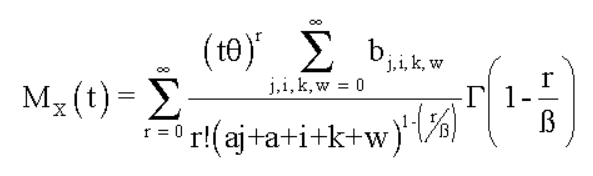

The sth incomplete moments, denoted by $\varphi_{\mathrm{S}}(\mathrm{t})$ of $\mathrm{X}$ is given by:

$$
\varphi_{s}(t)=\int_{0}^{t} x^{s} f(x) d x
$$

Using Eq. 6 and the lower incomplete gamma function, if $s<\beta$, we obtain:

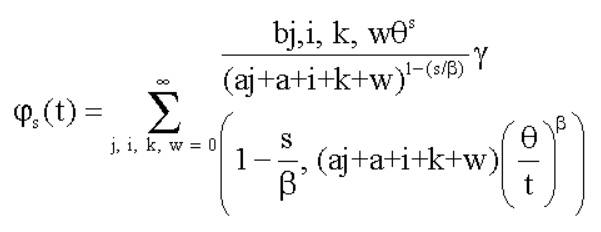

The first incomplete moment of $\mathrm{X}$, denoted by, $\varphi_{1}(\mathrm{t})$ is immediately calculated from Eq. 8 by setting $\mathrm{s}=1$.

Renyi and $\eta$-entropies: The Renyi entropy of $X$ represents a measure of variation of the uncertainty. The Renyi entropy is defined by:

$$
I_{\eta}(X)=\frac{1}{1-\eta} \log \int_{-\infty}^{\infty} f^{\eta}(x) d x, \eta>0 \text { and } \eta \neq 1
$$

Therefore, the Renyi entropy of a random variable $\mathrm{X}$ which follows the Kw-TMOF $(\mathrm{x}, \phi)$ is given by:

$$
\begin{aligned}
& I_{\eta}(X)=\frac{\log \left(\beta a b \theta^{\beta}\right)^{\eta}}{1-\eta} \\
& \sum_{j, i, k, w=0}^{\infty} t j, i, k, w \underbrace{\int_{0}^{\infty} x^{-\eta(1+\beta)} \exp \left[\begin{array}{c}
\text {-(-a } \underbrace{-a j-\eta+i+w)}\left(\frac{\theta}{x}\right)^{\beta}] d x \\
\underbrace{\beta}
\end{array}\right.}_{A}
\end{aligned}
$$

where:

$$
(-1)^{j+i+w} \Gamma(\eta b-\eta+1) \Gamma
$$

$$
\mathrm{tj}, \mathrm{i}, \mathrm{k}, \mathrm{w}=\frac{(\mathrm{aj}+\mathrm{a} \eta-\eta+1) \Gamma(2 \mathrm{aj}+2 \mathrm{a} \eta+\eta+\mathrm{k})}{\mathrm{j} ! \mathrm{i} ! \mathrm{k} ! \mathrm{w} ! \Gamma(\eta \mathrm{b}-(\eta+j)+1) \Gamma} \times
$$

$(a j+a \eta-\eta-i+1) \Gamma(2 a j+2 a \eta+\eta)$

$$
\frac{\Gamma(\eta+1)(\mathrm{ab})^{\eta}(\alpha \lambda+\alpha)^{\mathrm{aj}+\mathrm{a}-\mathrm{i}-\mathrm{w}}\left(1-\frac{1}{\alpha}\right)^{-2 \mathrm{aj}+2 \mathrm{a} \eta+\eta}}{\Gamma(\eta+1-\mathrm{w}) \alpha^{2 \mathrm{a}(\eta+\mathrm{j})}(\alpha \lambda+\alpha-1)^{-\mathrm{i}}(\alpha \lambda+\alpha+\lambda-1)^{-\mathrm{w}}}
$$

But:

$$
A=\frac{\theta^{1-\eta(1+\beta)}}{\beta(-\mathrm{a} \eta-\mathrm{aj}-\eta+\mathrm{i}+\mathrm{w})^{-(1-\lambda(1+\beta)) / \beta}} \Gamma\left(\frac{\eta(1+\beta)-1}{\beta}\right)
$$

and then:

$$
\begin{aligned}
& \mathrm{I}_{\lambda}(\mathrm{X})=\frac{1}{1-\eta} \log \\
& \left\{\left(\frac{\theta}{\beta}\right)^{1-\eta} \sum_{j, \mathrm{i}, \mathrm{k}, \mathrm{w}=0}^{\infty} \frac{\mathrm{t}_{\mathrm{j}, \mathrm{i}, \mathrm{k}, \mathrm{w}}}{(-\mathrm{a} \eta-\mathrm{aj}-\eta+\mathrm{i}+\mathrm{w})^{\mathrm{p}}} \Gamma(\mathrm{p})\right\}
\end{aligned}
$$

The $\eta$-entropy, say $H_{\eta}(X)$ is defined by:

$$
\begin{gathered}
\mathrm{H}_{\eta}(\mathrm{X})=\frac{1}{\eta-1} \log \left\{1-\int_{-\infty}^{\infty} \mathrm{f}^{\eta}(\mathrm{x}) \mathrm{dx}\right\}, \eta>0 \text { and } \eta \neq 1 \\
\mathrm{H}_{\eta}(\mathrm{X})=\frac{1}{\eta-1} \log \\
\left\{\left(\frac{\theta}{\beta}\right)^{1-\eta} \sum_{\mathrm{j}, \mathrm{i}, \mathrm{k}, \mathrm{w}=0}^{\infty} \frac{\mathrm{t}_{\mathrm{j}, \mathrm{i}, \mathrm{k}, \mathrm{w}}}{(-\mathrm{a} \eta-\mathrm{aj}-\eta+\mathrm{i}+\mathrm{w})^{\mathrm{p}}} \Gamma(\mathrm{p})\right\}
\end{gathered}
$$

where, $p=(\lambda \beta+\lambda-1) / \beta$.

Moments of residual and reversed residual lifes: The nth moments of residual life, denoted by $\mathrm{m}_{\mathrm{n}}(\mathrm{t})=\mathrm{E}\left((\mathrm{X}-\mathrm{t})^{\mathrm{n}} \mid \mathrm{X}>\mathrm{t}\right)$, $\mathrm{n}=1,2,3, \ldots$, is defined by $\mathrm{m}_{\mathrm{n}}(\mathrm{t})=\frac{1}{1-\mathrm{F}(\mathrm{t})} \int_{\mathrm{t}}^{\infty}(\mathrm{x}-\mathrm{t})^{\mathrm{n}} \mathrm{dF}(\mathrm{x})$.

Therefore, the nth moments of the residual life of $\mathrm{X}$ given that $r<\beta$ is given by: 


$$
\begin{aligned}
& m_{n}(t)=\frac{1}{R(t)} \sum_{r=0}^{n} \frac{(-1)^{n-t} \Gamma(n+1) t^{n-r} \theta^{r} \sum_{j, i, k, w=0}^{\infty} b_{j, i, k, w}}{\left.r ! \Gamma(n-r+1)(a j+a+i+k+w)^{1 \cdot(t / \beta / \beta}\right)} \\
& \gamma\left(1-\frac{r}{\beta},(a j+a+i+k+w)\left(\frac{\theta}{t}\right)^{\beta}\right)
\end{aligned}
$$

Here, we can use the upper incomplete gamma function defined by $\gamma(a, b)=\int_{b}^{-a} y^{-a-1} e^{-y} d y$. Another interesting function is the Mean Residual Life function (MRL) or the life expectancy at age $t$, defined by $m_{1}(x)=E((X-x) \mid X>x)$ and it represents the expected additional life length for a unit which is alive at age $\mathrm{x}$. The MRL of the Kw-TMOF distribution can be obtained by setting $n=1$ in the last equation. The nth moments of the reversed residual life, denoted by $\mathrm{Mn}(\mathrm{t})=\mathrm{E}\left((\mathrm{t}-\mathrm{X})^{n} \mid \mathrm{X} \leq \mathrm{t}\right)>0, \mathrm{n}=1,2,3, \ldots$, is given by $_{M_{n}(t)=\frac{1}{F(t)} \int_{0}^{t}(t-x)^{n} d F(x)}$. Therefore, the nth moments of the reversed residual life of a Kw-TMOF $(\alpha, \beta, \lambda, \eta)$ given that $r<\beta$ is given by:

$$
\begin{aligned}
& M_{n}(t)=\frac{1}{F(t)} \sum_{r=0}^{n} \frac{(-1)^{r} \Gamma(n+1) t^{n-r} \theta^{r} \sum_{j, i, k, w=0}^{\infty} b_{j, i, k, w}}{r ! \Gamma(n-r+1)(a j+a+i+k+w)^{1 \cdot(t / b)}} \\
& \gamma\left(1-\frac{r}{\beta},(a j+a+i+k+w)\left(\frac{\theta}{t}\right)^{\beta}\right)
\end{aligned}
$$

Here, we can use the lower incomplete gamma function defined by $\gamma(a, b)=\int_{b}^{-\infty} y^{a-1} e^{-y} d y$. The Mean Inactivity Time (MIT) or Mean Waiting Time (MWT) also called mean reversed residual life function, defined by $\mathrm{M}_{1}(\mathrm{t})=$ $\mathrm{E}((\mathrm{t}-\mathrm{X}) \mid \mathrm{X} \leq \mathrm{t})$ and it represents the waiting time elapsed, since, the failure of an itemon condition that this failure had occurred in $(0, x)$. The MRRL of the $\mathrm{Kw}-\mathrm{TMOF}$ distribution can be obtained by setting $\mathrm{n}=1$.

Order statistics: The order statistics and their moments have great importance in many statistical problems and they have many applications in reliability analysis and life testing. The order statistics arise in the study of reliability of a system. The order statistics can represent the lifetimes of units or components of a reliability system. Let $\mathrm{X}_{1}, \mathrm{X}_{2}, \ldots, \mathrm{X}_{\mathrm{n}}$ be a random sample of size $\mathrm{n}$ from the $\mathrm{Kw}$-TMOF $(\phi, \mathrm{x})$ with cdf and pdf as in (3) and (4), respectively. Let $\mathrm{X}_{(1)}, \mathrm{X}_{(2)}, \ldots, \mathrm{X}_{(\mathrm{n})}$ be the corresponding order statistics. Then the pdf of $j$ th order statistics, say $Y=X_{(: n)}, 1 \leq j \leq n$, denoted by $f_{\gamma}(x)$ is given by:

$$
\begin{aligned}
& f_{Y}(x)=\frac{n ! a b \alpha \beta \theta^{\beta} x^{-(\beta+1)}}{(j-1) !(n-j) !} \\
& \frac{\alpha(1+\lambda) \exp \left[-\left(\frac{\theta}{x}\right)^{\beta}\right]-(\alpha \lambda+\alpha+\lambda-1) \exp \left[-2\left(\frac{\theta}{x}\right)^{\beta}\right]}{\left\{\alpha+(1-\alpha) \exp \left[-\left(\frac{\theta}{x}\right)^{\beta}\right]\right\}^{2 a+1}\left\{\frac{\alpha(1+\lambda)}{\exp \left[\left(\frac{\theta}{x}\right)^{\beta}\right]}-\frac{(\alpha \lambda+\alpha-1)}{\exp \left[2\left(\frac{\theta}{x}\right)^{\beta}\right]}\right\}^{1-\alpha}} \times \\
& \left.\left\{1-\left(\frac{\alpha(1+\lambda) \exp \left[-\left(\frac{\theta}{\mathrm{x}}\right)^{\beta}\right]-(\alpha \lambda+\alpha-1) \exp \left[-2\left(\frac{\theta}{\mathrm{x}}\right)^{\beta}\right]}{\left(\alpha+(1-\alpha) \exp \left[-\left(\frac{\theta}{\mathrm{x}}\right)^{\beta}\right]\right)^{2}}\right)^{a}\right\}^{b(\mathrm{n} \cdot \mathrm{-}+1)-1}\right\}^{x} \\
& \left\{1-\left[1-\left[\frac{\alpha(1+\lambda) \exp \left[-\left(\frac{\theta}{x}\right)^{\beta}\right]-(\alpha \lambda+\alpha-1) \exp \left[-2\left(\frac{\theta}{x}\right)^{\beta}\right]}{\left(\alpha+(1-\alpha) \exp \left[-\left(\frac{\theta}{x}\right)^{\beta}\right]\right)^{2}}\right]\right\}^{b}\right\}^{j-1}
\end{aligned}
$$

The pdf of $Y$ in Eq. 9 can be expressed as a mixture of Frechet densities as:

$$
f_{Y}(x)=\sum_{r, i, 1, h, w}^{\infty} \xi_{r, i, 1, h, w} g\left(x ; \beta, \theta(a i+a+i+1+h+w)^{1 / \beta}\right)
$$

where, $g\left(x ; \beta, \theta(a i+a+i+1+h+w)^{1 / \beta}\right)$ denotes to the Frechet pdf with parameters $\left.\beta, \theta(a+a+i+1+h+w)^{1 / \beta}\right)$ and:

$$
\begin{aligned}
& \mathrm{n} ! \mathrm{ab}(-1)^{\mathrm{rti+1+h}} \Gamma(2 \mathrm{ai}+2 \mathrm{a}+1+\mathrm{w}) \alpha^{-2 \mathrm{a}(\mathrm{i}+1)}(\alpha \lambda+\alpha-1)^{\mathrm{h}} \\
& \xi_{j, i, k, w}=\frac{\left(\begin{array}{l}
b(n+r-j+1)-1 \\
i
\end{array}\right)\left(\begin{array}{l}
j-1 \\
r
\end{array}\right)\left(\begin{array}{l}
a(i+1)-1 \\
h
\end{array}\right)\left(1-\frac{1}{\alpha}\right)^{w}}{(j-1) !(n-j) ! 1 ! w ! \Gamma(2-1) \Gamma(2 a i+2 a+1)} \\
& (\mathrm{ai}+\mathrm{a}+\mathrm{i}+1+\mathrm{h}+\mathrm{w})(\alpha \lambda+\alpha+\lambda-1)^{-1}(\alpha \lambda+\alpha)^{-(\alpha+a-1-h)}
\end{aligned}
$$

Therefore, the qth moment of $Y$ can be expressed as:

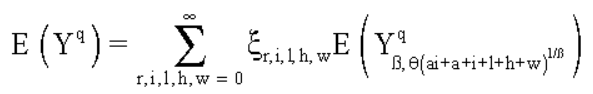

where, $Y_{\beta, \theta(a+d+1+h++w)}^{1 / \beta}$ Frechet $\left(\beta, \theta(a i+a i+1+h+w)^{1 / \beta}\right)$.

Characterization: Characterizations of distributions is an important research area which has recently attracted 
the attention of many researchers. This study deals with a characterization of $\mathrm{Kw}-\mathrm{TMOF}$ distribution. This characterization is in terms of a truncated moment of a function of the random variable. Our characterization result employs a special case of a theorem due to Glanzel (1987), Theorem 1 by note that the result holds also when the interval $\mathrm{H}$ is not closed. Moreover, it could be also applied when the cdf $\mathrm{F}$ does not have a closed form. As shown by Glanzel (1990), this characterization is stable in the sense of weak convergence.

Theorem 1: Let $(\Omega, F, P)$ be a given probability space and let $\mathrm{H}=[\mathrm{d}$, e] be an interval for some $\mathrm{d}<\mathrm{e}(\mathrm{d}=-\infty, \mathrm{e}=\infty$ mightaswellbeallowed). Let X: $\Omega \rightarrow \mathrm{H}$ be a continuous random variable with the distribution function $\mathrm{F}$ and let $\mathrm{g}$ be a real function defined on $\mathrm{H}$ such that:

$$
\mathrm{E}[\mathrm{g}(\mathrm{X}) \mid \mathrm{X} \geq \mathrm{x}]=\xi(\mathrm{x}), \mathrm{x} \in \mathrm{H}
$$

Is defined with some real function $\xi$. Assume that $\mathrm{g} \in \mathrm{C}^{1}(\mathrm{H}), \quad \xi \in \mathrm{C}^{2}(\mathrm{H})$ and $\mathrm{F}$ is twice continuously differentiable and strictly monotone function on the set $\mathrm{H}$. Finally, assume that the equation $\xi=\mathrm{g}$ has no real solution in the interior of $\mathrm{H}$. Then $\mathrm{F}$ is uniquely determined by the functions $g$ and $\xi$, particularly:

$$
F(x)=\int_{a}^{\mathrm{z}} \mathrm{C}\left|\frac{\xi^{\prime}(\mathrm{u})}{\xi(\mathrm{u})-\mathrm{g}(\mathrm{u})}\right| \exp (-\mathrm{s}(\mathrm{u})) \mathrm{du}
$$

where, the function $\mathrm{s}$ is a solution of the differential equation $\mathrm{s}^{\prime}=\xi^{\prime} / \xi$-g and $\mathrm{C}$ is the normalization constant, such that $\int_{\mathrm{H}} \mathrm{dF}=1$. Here is our first characterization.

Proposition 1: Let X: $\Omega \rightarrow(0, \infty)$ be a continuous random variable and let:

$$
g(x)=\left\{1-\frac{\left[\alpha(1+\lambda) e^{-(\theta / x)^{\beta}}-(\alpha \lambda+\alpha-1) \mathrm{e}^{-2(\theta / x)^{\beta}}\right]^{\alpha-1}}{\left[\alpha+(1-\alpha) \mathrm{e}^{-(\theta / x)^{\beta}}\right]^{2 a}}\right\}, \text { for } \mathrm{x}>0
$$

The random variable $\mathrm{X}$ belongs to $\mathrm{Kw}-\mathrm{TMOF}$ family (Eq. 4) $\xi$ if and only, if the function $\xi$ defined in theorem 1 has the form:

$$
\xi(\mathrm{x})=\frac{\mathrm{b}}{\mathrm{b}+1}\left\{1-\left(\frac{\alpha(1+\lambda) \mathrm{e}^{-(\theta / z)^{\beta}}-(\alpha \lambda+\alpha-1) \mathrm{e}^{-2(\theta / \mathrm{x})^{\beta}}}{\left[\alpha+(1-\alpha) \mathrm{e}^{-(\theta / x)^{\beta}}\right]^{2}}\right)\right\}, \mathrm{x}>0
$$

Proof: Let X be a random variable with pdf (Eq. 4), then:

$$
\begin{aligned}
& (1-F(x)) E[g(x) \mid \mathrm{X} \geq \mathrm{x}]= \\
& \int_{\mathrm{x}}^{\infty} \mathrm{f}(\mathrm{u})\left\{1-\frac{\left[\alpha(1+\lambda) \mathrm{e}^{-(\theta / \mu)^{\beta}}-(\alpha \lambda+\alpha-1) \mathrm{e}^{-2(\theta / \mu)^{\beta}}\right]^{\mathrm{a}-1}}{\left[\alpha+(1-\alpha) \mathrm{e}^{-(\theta / u)^{\beta}}\right]^{2 a}}\right\} \mathrm{du}= \\
& \frac{\mathrm{b}}{\mathrm{b}+1}\left\{1-\left(\frac{\alpha(1+\lambda) \mathrm{e}^{-(\theta / x)^{\beta}}-(\alpha \lambda+\alpha-1) \mathrm{e}^{-2(\theta / x)^{\beta}}}{\left[\alpha+(1-\alpha) \mathrm{e}^{-(\theta / x)^{\beta}}\right]^{2}}\right]^{\mathrm{b}+1}, \mathrm{x}>0\right.
\end{aligned}
$$

and:

$$
\begin{aligned}
& \xi(\mathrm{x})-\mathrm{g}(\mathrm{x})= \\
& -\frac{1}{\mathrm{~b}+1}\left\{1-\left(\frac{\alpha(1+\lambda) \mathrm{e}^{-(\theta / x)^{\beta}}-(\alpha \lambda+\alpha-1) \mathrm{e}^{-2\left(\theta / x \mathrm{x}^{\beta}\right.}}{\left[\alpha+(1-\alpha) \mathrm{e}^{-(\theta / \mathrm{x})^{\beta}}\right]^{2}}\right)\right\} \\
& <0, \text { for } \mathrm{x}>0
\end{aligned}
$$

Conversely, if $\xi$ is given as above, then:

$$
\begin{aligned}
& \mathrm{s}^{\prime}(\mathrm{x})=\frac{\xi^{\prime}(\mathrm{x})}{\xi(\mathrm{x})-\mathrm{g}(\mathrm{x})}= \\
& \frac{\operatorname{ba\alpha \beta \beta \theta ^{\beta }} \mathrm{x}^{-\beta-1}\left[\alpha(1+\lambda) \mathrm{e}^{-(\theta / u)^{\beta}}-(\alpha \lambda+\alpha+\lambda-1) \mathrm{e}^{-2(\theta / u)^{\beta}}\right]}{\left[\alpha+(1-\alpha) \mathrm{e}^{-(\theta / \mu)^{\beta}}\right]^{2 \alpha+1}} \times \\
& \left\{1-\left(\frac{\alpha(1+\lambda) \mathrm{e}^{-\left(\theta / x \mathrm{z}^{\beta}\right.}-(\alpha \lambda+\alpha-1) \mathrm{e}^{-2(\theta / x)^{\beta}}}{\left[\alpha+(1-\alpha) \mathrm{e}^{-(\theta / z)^{\beta}}\right]^{2}}\right)\right\} \\
& {\left[\alpha(1+\lambda) \mathrm{e}^{-(\theta / \mu)^{\beta}}-(\alpha \lambda+\alpha-1) \mathrm{e}^{-2(\theta / u)^{\beta}}\right]^{\alpha-1}}
\end{aligned}
$$

and hence:

$$
\mathrm{s}(\mathrm{x})=-\operatorname{blog}\left\{1-\left(\frac{\alpha(1+\lambda) \mathrm{e}^{-\left(\theta / x x^{\beta}\right.}-(\alpha \lambda+\alpha-1) \mathrm{e}^{-2(\theta / x)^{\beta}}}{\left[\alpha+(1-\alpha) \mathrm{e}^{-(\theta / z)^{\beta}}\right]^{2}}\right]^{\mathrm{a}}\right\},
$$

$\mathrm{x}>0$

Now in view of theorem 1, X has density (Eq. 4).

Corollary 2: Let X: $\Omega \rightarrow(0, \infty)$ be a continuous random variable. The pdf of $X$ is (Eq. 4) if and only if there exist functions $\mathrm{g}$ and $\xi$ defined in theorem 1 satisfying the differential equation: 


$$
\begin{gathered}
\frac{\xi^{\prime}(\mathrm{x})}{\xi(\mathrm{x})-\mathrm{g}(\mathrm{x})}=\frac{\left[\alpha(1+\lambda) \mathrm{e}^{-(\theta / u)^{\beta}}-(\alpha \lambda+\alpha+\lambda-1) \mathrm{e}^{-2(\theta / u)^{\beta}}\right]}{\left[\alpha+(1-\alpha) \mathrm{e}^{-(\theta / u)^{\beta}}\right]^{2 \mathrm{a}+1}} \times \\
\left\{1-\left(\frac{\alpha(1+\lambda) \mathrm{e}^{-(\theta / x)^{\beta}}-(\alpha \lambda+\alpha-1) \mathrm{e}^{-2(\theta / x)^{\beta}}}{\left[\alpha+(1-\alpha) \mathrm{e}^{-(\theta / x)^{\beta}}\right]^{2}}\right)\right\} \\
{\left[\alpha(1+\lambda) \mathrm{e}^{-(\theta / u)^{\beta}}-(\alpha \lambda+\alpha-1) \mathrm{e}^{-2(\theta / u)^{\beta}}\right]^{\alpha-1}}
\end{gathered}
$$

The general solution of the differential equation in corollary 2 is:

$$
\begin{aligned}
& \xi(\mathrm{x})=\left\{1-\left(\frac{\alpha(1+\lambda) \mathrm{e}^{-(\theta / x)^{\beta}}-(\alpha \lambda+\alpha-1) \mathrm{e}^{-2(\theta / x)^{\beta}}}{\left[\alpha+(1-\alpha) \mathrm{e}^{-(\theta / x)^{\beta}}\right]^{2}}\right\}^{\mathrm{a}}\right\}^{-b} \\
& {\left[\begin{array}{l}
-\int \frac{\text { ba } \alpha \beta \theta^{\beta} \mathrm{x}^{-\beta-1}\left[\alpha(1+\lambda) \mathrm{e}^{-(\theta / u)^{\beta}}-(\alpha \lambda+\alpha+\lambda-1) \mathrm{e}^{-2(\theta / u)^{\beta}}\right]_{x}}{\left[\alpha+(1-\alpha) \mathrm{e}^{-(\theta / u)^{\beta}}\right]^{2 a+1}} \\
{\left[\alpha(1+\lambda) \mathrm{e}^{-(\theta / u)^{\beta}}-(\alpha \lambda+\alpha-1) \mathrm{e}^{-2(\theta / u)^{\beta}}\right]^{\alpha-1} \times} \\
\left\{1-\left(\frac{\alpha(1+\lambda) \mathrm{e}^{-(\theta / x)^{\beta}}-(\alpha \lambda+\alpha-1) \mathrm{e}^{-2(\theta / z)^{\beta}}}{\left[\alpha+(1-\alpha) \mathrm{e}^{-(\theta / z)^{\beta}}\right]^{2}}\right]^{\mathrm{a}}\right\}^{b-1} \mathrm{~g}(\mathrm{x}) \mathrm{dx}+\mathrm{D}
\end{array}\right]}
\end{aligned}
$$

where, D is a constant. Note that, a set of functions satisfying the differential Eq. 10 is given in proposition 1 with $\mathrm{D}=0$. However, it should be also noted that there are other pairs $(\mathrm{g}, \xi)$ satisfying the conditions of theorem 1 .

Estimation: The Maximum Likelihood Estimators (MLEs) for the parameters of the Kw-TMOF is discussed in this study. Let $\mathrm{x}_{1}, \ldots, \mathrm{x}_{\mathrm{n}}$ be a random sample of this distribution with unknown parameter vector $\phi=(\alpha, \beta, \theta, \lambda, \mathrm{a}, \mathrm{b})^{\mathrm{T}}$. Then, the log-likelihood function for $\phi, \ell=\ell(\phi)$ is:

$$
\begin{aligned}
& \ell=\mathrm{n}(\ln \mathrm{a}+\ln \mathrm{b}+\ln \alpha+\ln \beta+\beta \ln \theta)- \\
& (\beta+1) \sum_{\mathrm{i}=1}^{\mathrm{n}} \ln \mathrm{x}_{\mathrm{i}}-\theta^{\beta} \sum_{\mathrm{i}=1}^{\mathrm{n}} \mathrm{x}_{\mathrm{i}}^{\beta}+ \\
& \sum_{\mathrm{i}=1}^{\mathrm{n}} \ln \mathrm{l}_{\mathrm{i}}+(\mathrm{a}-1) \sum_{\mathrm{i}=1}^{\mathrm{n}} \ln \mathrm{k}_{\mathrm{i}}-(2 \mathrm{a}+1) \\
& \sum_{\mathrm{i}=1}^{\mathrm{n}} \ln \mathrm{z}_{\mathrm{i}}+(\mathrm{b}-1) \sum_{\mathrm{i}=1}^{\mathrm{n}} \ln \mathrm{q}_{\mathrm{i}}
\end{aligned}
$$

where:

$$
\begin{aligned}
& 1_{\mathrm{i}}=\alpha(1+\lambda)-(\lambda+\mathrm{p}) \mathrm{s}_{\mathrm{i}}, \mathrm{k}_{\mathrm{i}}=\alpha(1+\lambda) \mathrm{s}_{\mathrm{i}}-\mathrm{ps}_{\mathrm{i}}^{2}, \mathrm{p}=\alpha \lambda+\alpha-1, \\
& \mathrm{z}_{\mathrm{i}}=\alpha+(1-\alpha) \mathrm{s}_{\mathrm{i}}, \mathrm{q}_{\mathrm{i}}=1-\left(\frac{\mathrm{k}_{\mathrm{i}}}{\mathrm{z}_{\mathrm{i}}^{2}}\right)^{\mathrm{a}} \text { and } \mathrm{s}_{\mathrm{i}}=\exp \left[-\left(\frac{\theta}{\mathrm{x}_{\mathrm{i}}}\right)^{\beta}\right]
\end{aligned}
$$

The elements of score vector, $\mathrm{U}(\phi)=\partial \ell / \partial \phi=(\partial \ell / \partial \alpha$, $\partial \ell / \partial \beta, \partial \ell / \partial \lambda, \partial \ell / \partial \theta, \partial \ell / \partial \mathrm{a}, \partial \ell / \partial \mathrm{b})^{\mathrm{T}}$ are given by:

$$
\begin{aligned}
& \frac{\partial \ell}{\partial \alpha}=\frac{\mathrm{n}}{\alpha}+\sum_{\mathrm{i}=1}^{\mathrm{n}} \frac{(1+\lambda)}{1_{\mathrm{i}}\left(1-\mathrm{s}_{\mathrm{i}}\right)^{-1}}+(\mathrm{a}-1) \sum_{\mathrm{i}=1}^{\mathrm{n}} \frac{(1+\lambda)}{\mathrm{k}_{\mathrm{i}}\left(1-\mathrm{s}_{\mathrm{i}}\right)^{-1}}+ \\
& (2 \mathrm{a}+1) \sum_{\mathrm{i}=1}^{\mathrm{n}} \frac{(1+\alpha) \ln \left(\frac{\theta}{\mathrm{x}_{i}}\right)}{\mathrm{k}_{\mathrm{i}} \mathrm{s}_{\mathrm{i}}^{-1}\left(\frac{\theta}{\mathrm{x}_{\mathrm{i}}}\right)^{-1}}-(\mathrm{b}-1) \sum_{\mathrm{i}=1}^{\mathrm{n}} \frac{\mathrm{al}_{\mathrm{i}}\left(1-\mathrm{q}_{\mathrm{i}}\right)^{\frac{\mathrm{a}-1}{\mathrm{a}}}}{\mathrm{z}_{\mathrm{i}}^{3} \mathrm{q}_{\mathrm{i}}} \\
& \frac{\partial \ell}{\partial \beta}=n\left(\frac{1}{\beta}+\ln \theta\right)-\sum_{i=1}^{n} \ln x_{i}-\sum_{i=1}^{n} \frac{\ln \left(\theta x_{i}\right)}{\left(\theta x_{i}\right)^{-\beta}}+\sum_{i=1}^{n} \frac{(p+\lambda) \ln \frac{\beta}{\theta}}{1_{i} s_{i}^{-1}\left(\frac{\theta}{x_{i}}\right)^{-\beta}}- \\
& (a-1) \sum_{i=1}^{n} \frac{\ln \frac{\beta}{\theta}\left[\mathrm{ps}_{\mathrm{i}}^{2}-\mathrm{k}_{\mathrm{i}}\right]}{\mathrm{k}_{\mathrm{i}}\left(\frac{\theta}{\mathrm{x}_{\mathrm{i}}}\right)^{-\beta}}+(2 \mathrm{a}-1) \sum_{\mathrm{i}=1}^{\mathrm{n}} \frac{(1+\mathrm{a}) \ln \left(\frac{\theta}{\mathrm{x}_{\mathrm{i}}}\right)}{\mathrm{z}_{\mathrm{i}} \mathrm{s}_{\mathrm{i}}^{-1}\left(\frac{\theta}{\mathrm{x}_{\mathrm{i}}}\right)^{-\beta}}+ \\
& \mathrm{a}(\mathrm{b}-1) \sum_{\mathrm{i}=1}^{\mathrm{n}} \frac{\mathrm{l}_{\mathrm{i}}\left(\frac{\theta}{\mathrm{x}_{\mathrm{i}}}\right)^{\beta}\left(1-\mathrm{q}_{\mathrm{i}}\right)^{\frac{\mathrm{a}-1}{a}} \ln \left(\frac{\theta}{\mathrm{x}_{\mathrm{i}}}\right)}{\mathrm{q}_{\mathrm{i}} \mathrm{s}_{\mathrm{i}}^{-1} \mathrm{z}_{\mathrm{i}}^{3}} \\
& \frac{\partial \ell}{\partial \theta}=\frac{n \beta}{\theta}-\beta \theta^{\beta-1} \sum_{i=1}^{n} x_{i}^{\beta}+\sum_{i=1}^{n} \frac{(p+\lambda) \frac{\beta}{\theta}}{1_{i} s_{i}^{-1}\left(\frac{\theta}{x_{i}}\right)^{-\beta}}+(a-1) \frac{\beta}{\theta} \sum_{i=1}^{n} \frac{\left(\mathrm{ps}_{i}^{2}-k_{i}\right)}{k_{i}\left(\frac{\theta}{x_{i}}\right)^{-\beta}} \\
& (1-\alpha)(2 \mathrm{a}-1) \sum_{\mathrm{i}=1}^{\mathrm{n}} \frac{\frac{\beta}{\theta}\left(\frac{\theta}{\mathrm{x}_{i}}\right)^{\beta}}{\mathrm{z}_{\mathrm{i}} \mathrm{s}_{\mathrm{i}}^{-1}}+\mathrm{a} \alpha \beta(\mathrm{b}-1) \sum_{\mathrm{i}=1}^{\mathrm{n}} \frac{\mathrm{l}_{\mathrm{i}}\left(1-\mathrm{q}_{\mathrm{i}}\right)^{\frac{\mathrm{a}-1}{a}}}{\theta \mathrm{q}_{\mathrm{i}} \mathrm{s}_{\mathrm{i}}{ }^{-1} \mathrm{z}_{\mathrm{i}}^{3}\left(\frac{\theta}{\mathrm{x}_{\mathrm{i}}}\right)^{-\beta}} \\
& \frac{\partial \ell}{\partial \mathrm{a}}=\frac{\mathrm{n}}{\mathrm{a}}+\sum_{\mathrm{i}=1}^{\mathrm{n}} \ln \mathrm{k}_{\mathrm{i}}-2 \sum_{\mathrm{i}=1}^{\mathrm{n}} \ln \mathrm{z}_{\mathrm{i}}+(\mathrm{b}-1) \sum_{\mathrm{i}=1}^{\mathrm{n}} \frac{\left(2 \ln \mathrm{z}_{\mathrm{i}}-\operatorname{lnk}_{\mathrm{i}}\right)}{\mathrm{q}_{\mathrm{i}}\left(1-\mathrm{q}_{\mathrm{i}}\right)^{-1}} \\
& \frac{\partial \ell}{\partial \lambda}=\sum_{\mathrm{i}=1}^{\mathrm{n}} \frac{\alpha-(\alpha+1) \mathrm{s}_{\mathrm{i}}}{1_{\mathrm{i}}}+(\mathrm{a}-1) \sum_{\mathrm{i}=1}^{\mathrm{n}} \frac{\alpha\left(1-\mathrm{s}_{\mathrm{i}}\right)}{\mathrm{k}_{\mathrm{i}} \mathrm{s}_{\mathrm{i}}^{-1}}+\mathrm{a} \alpha(\mathrm{b}-1) \\
& \sum_{i=1}^{\mathrm{n}} \frac{\left(1-\mathrm{q}_{i}\right)^{\frac{\mathrm{a}-1}{\mathrm{a}}}}{\mathrm{q}_{\mathrm{i}} \mathrm{s}_{\mathrm{i}}^{-1} \mathrm{z}_{\mathrm{i}}^{2}\left(\mathrm{~s}_{\mathrm{i}}-1\right)^{-1}}
\end{aligned}
$$




$$
\frac{\partial \ell}{\partial \beta}=\frac{\mathrm{n}}{\mathrm{b}}+\sum_{\mathrm{i}=1}^{\mathrm{n}} \ln \mathrm{q}_{\mathrm{i}}
$$

where:

$$
\mathrm{d}_{\mathrm{i}}=\alpha(\lambda+1) \mathrm{s}_{\mathrm{i}}-2 \mathrm{k}_{\mathrm{i}}
$$

We can find the estimates of the unknown parameters by setting the score vector to zero, $\mathrm{U}(\hat{\phi})=0$ and solving them simultaneously yields the $\mathrm{ML}$ estimators $\hat{\alpha}, \widehat{\beta}, \hat{\theta}, \hat{\lambda}, \hat{\alpha}$ and $\hat{b}$. These equations cannot be solved analytically and statistical software can be used to solve them numerically by means of iterative techniques such as the Newton-Raphson algorithm. For the five parameters $\mathrm{Kw}$-TMOF distribution all the second order derivatives exist. Setting these above equations to zero and solving them simultaneously also yield the MLEs of the 6 parameters.

For interval estimation of the model parameters, we require the $6 \times 6$ observed information matrix $\mathrm{J}(\phi)=\left\{\mathrm{J}_{\mathrm{rs}}\right\}$ $\{$ for $\mathrm{r}, \mathrm{s}=\alpha, \beta, \theta, \lambda, \mathrm{a}, \mathrm{b}\}$ given in Appendix A. Under standard regularity conditions, the multivariate normal $\mathrm{N}_{6}\left(0, \mathrm{~J}(\hat{\phi})^{-1}\right)$ distribution can be used to construct approximate confidence intervals for the model parameters. Here, $\mathrm{J}(\hat{\phi})$ is the total observed information matrix evaluated at $\hat{\phi}$. Therefore, approximate $100(1-\phi) \%$ confidence intervals for $\alpha, \beta, \theta, \lambda$, a and $\mathrm{b}$ can be determined as:

$$
\begin{aligned}
& \hat{\alpha} \pm Z_{\frac{\Phi}{2}} \sqrt{J_{\alpha \alpha}}, \hat{\beta} \pm Z_{\frac{\phi}{2}} \sqrt{J_{\beta \beta}}, \hat{\theta} \pm Z_{\frac{\phi}{2}} \sqrt{J_{\theta \theta}} \\
& \hat{\lambda} \pm Z_{\frac{\phi}{2}} \sqrt{J_{\lambda \lambda}}, \hat{a} \pm Z_{\frac{\Phi}{2}} \sqrt{J_{\mathrm{aa}}} \text {, and } \hat{b} \pm Z_{\frac{\phi}{2}} \sqrt{J_{b b}}
\end{aligned}
$$

where, $Z \phi / 2$ is the upper $\phi$ th percentile of the standard normal distribution.

\section{RESULTS AND DISCUSSION}

Data analysis: In this study, we provide two applications of the Kw-TMOF distribution to show its importance. We now provide a data analysis in order to assess the goodness-of-fit of the new model. For the two real data sets we shall compare the fits of the Kw-TMOF Model with 6 of its sub models: the KMOIE, KMOIR, TMOF,
$\mathrm{MOF}, \mathrm{TF}$ and Frechet distributions to show the potential of the new distribution. Moreover, we shall compare the proposed distribution with two non-nested models: Gamma Extended Frechet (GEF) (Da Silva et al., 2013) and Beta Frechet (BF) (Barreto-Souza et al., 2011) distributions with corresponding densities given (for $\mathrm{x}>0$ ) by:

$$
\begin{aligned}
& \text { BFr: } f(x)=\frac{\beta \theta^{\beta}}{B(a, b)} x^{(-\beta-1)} e^{-a\left(\frac{\theta}{x}\right)^{\beta}}\left[1-e^{-a\left(\frac{\theta}{x}\right)^{\beta}}\right]^{b-1} \\
& \text { GEFr: } f(x)=\frac{a \beta \theta^{\beta}}{\Gamma(b)} x^{-\beta-1} e^{-\left(\frac{\theta}{x}\right)^{\beta}}\left[1-e^{\left.-a\left(\frac{\sigma}{x}\right)^{\beta}\right]^{a-1}}\right. \\
& \left\{-\log \left[1-e^{-\left(\frac{\theta}{x}\right)^{a}}\right]^{b-1}\right\}
\end{aligned}
$$

where, $\beta, \theta$, a and $\mathrm{b}$ are positive parameters.

Data set 1; Glass fibres: The first data set is obtained from Smith and Naylor (1987). The data are the strengths of $1.5 \mathrm{~cm}$ glass fibres, measured at the National Physical Laboratory, England. Unfortunately, the units of measurement are not given in the study.

Data set 2; Carbon fibres: The second data set corresponds to an uncensored data set from Nichols and Padgett (2006) on breaking stress of carbon fibres (in Gba). This data set was previously studied by Afify et al. (2014a, b) to fit the transmuted complementary Weibull geometric distribution.

Model selection: The model selection is carried out using goodness-of-fit measures including the Akaike Information Criterion (AIC), Consistent Akaike Information Criterion (CAIC), Bayesian Information Criterion (BIC), Hannan-Quinn Information Criterion (HQIC) and $-2 \ell$ (where, $\ell$ is maximized log-likelihood).

\begin{tabular}{|c|c|c|c|c|c|}
\hline Model & $-2 \hat{\rho}$ & $\mathrm{AIC}$ & $\mathrm{BIC}$ & HQIC & CAIC \\
\hline Kw-TMOF & 43.775 & 55.775 & 68.634 & 60.833 & 57.275 \\
\hline TMOF & 48.46 & 56.46 & 65.032 & 59.831 & 57.149 \\
\hline KTMOIE & 54.572 & 64.572 & 75.287 & 68.786 & 65.624 \\
\hline $\mathrm{BF}$ & 60.63 & 68.63 & 77.202 & 72.002 & 69.32 \\
\hline GEF & 61.557 & 69.557 & 78.13 & 72.929 & 70.247 \\
\hline MOF & 95.738 & 101.738 & 108.168 & 104.267 & 102.145 \\
\hline $\mathrm{TF}$ & 94.078 & 100.078 & 106.507 & 102.606 & 100.484 \\
\hline $\mathrm{F}$ & 93.707 & 97.707 & 101.993 & 99.392 & 97.907 \\
\hline
\end{tabular}

Table 2-4 list the numerical values of the $-2 \ell$, AIC, $\mathrm{BIC}, \mathrm{HQIC}$ and CAIC using the first data set, whilst the MLEs and their corresponding standard errors (in parentheses) of the model parameters are shown in Table 3 and 5 . These numerical results are obtained using

Table 2: The statistics and for data set 1 
(a)

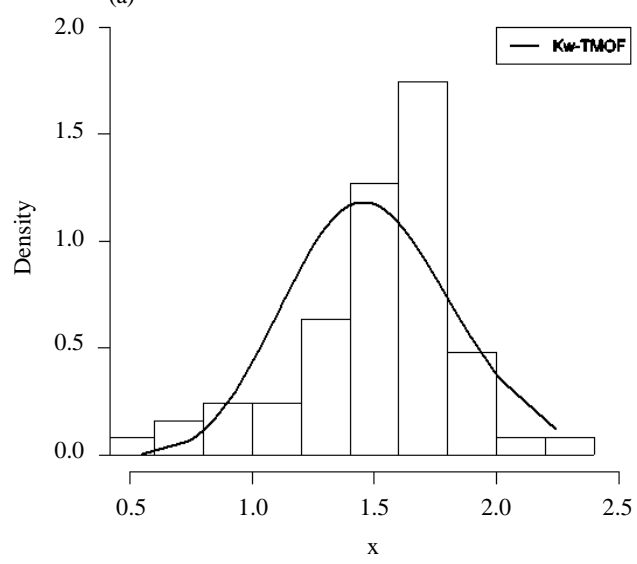

(b)

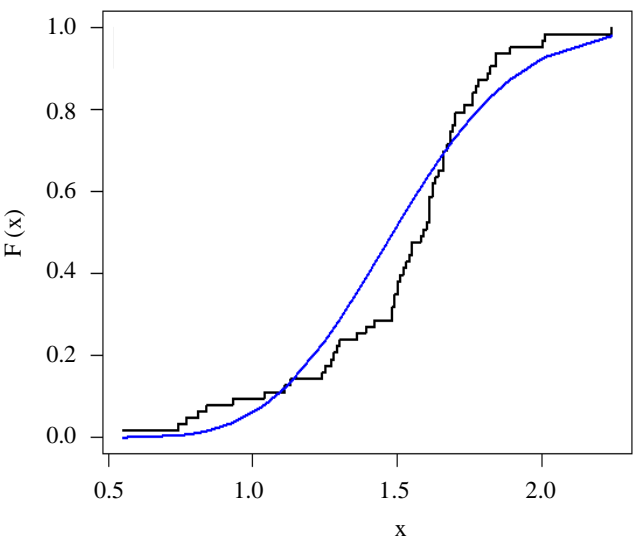

Fig. 3: The estimated pdf and cdf of the Kw-TMOF Model for data set 1: a) Kw-TMOF and b) Kw-MOF
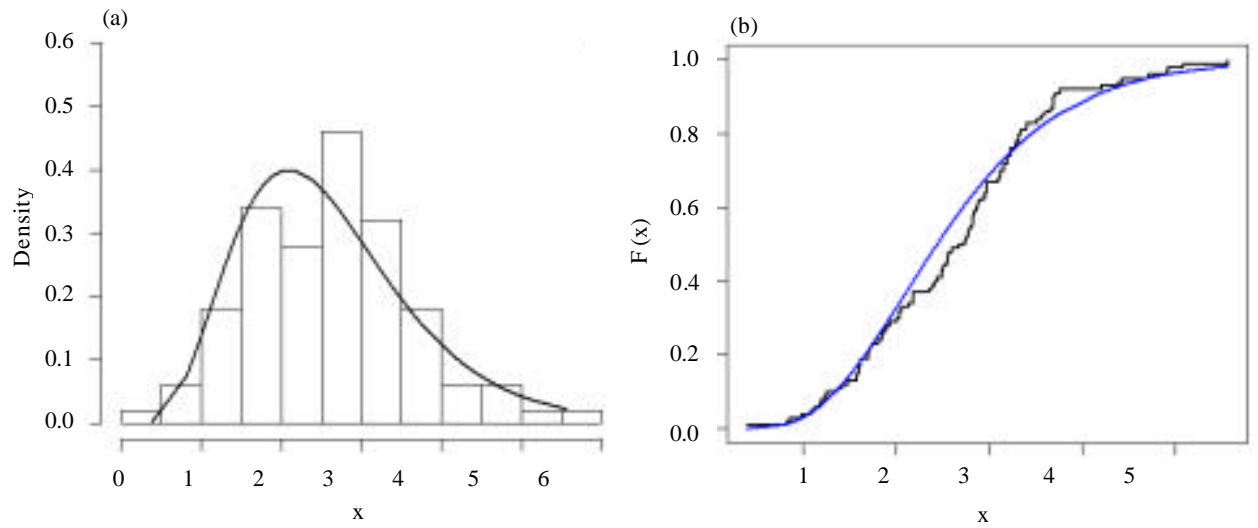

Fig. 4: The estimated pdf and cdf of the Kw-TMOF model for data set 2: a) Kw-TMOF and b) Kw-MOF

Table 3: MLEs and their standard errors (in parentheses) for data set I

$$
\text { Estimates }
$$

\begin{tabular}{|c|c|c|c|c|c|c|}
\hline Models & $\hat{\alpha}$ & $\hat{\beta}$ & $\hat{\theta}$ & $\hat{\lambda}$ & $\hat{a}$ & $\hat{\mathrm{h}}$ \\
\hline Kw-TMOF & $\begin{array}{l}1.0017 \\
(0.961)\end{array}$ & $\begin{array}{l}0.9451 \\
(0.244)\end{array}$ & $\begin{array}{l}2.3330 \\
(1.498)\end{array}$ & $\begin{array}{l}-5.4912 \times 10^{5} \\
(0.024)\end{array}$ & $\begin{array}{l}3.4721 \\
(0.046)\end{array}$ & $\begin{array}{l}142.4414 \\
(9.162)\end{array}$ \\
\hline TMOF & $\begin{array}{l}376.268 \\
(246.832)\end{array}$ & $\begin{array}{l}6.8744 \\
(0.596)\end{array}$ & $\begin{array}{l}0.65 \\
(0.049)\end{array}$ & $\begin{array}{l}0.1499 \\
(0.302)\end{array}$ & $\begin{array}{l}-- \\
--\end{array}$ & $\begin{array}{l}-- \\
--\end{array}$ \\
\hline KTMOIE & $\begin{array}{l}0.4057 \\
(0.064)\end{array}$ & $\begin{array}{l}-- \\
--\end{array}$ & $\begin{array}{l}1.8859 \\
(0.766)\end{array}$ & $\begin{array}{l}-10 \times 10^{-5} \\
(0.396)\end{array}$ & $\begin{array}{l}4.788 \\
(2.401)\end{array}$ & $\begin{array}{l}21.8011 \\
(8.284)\end{array}$ \\
\hline $\mathrm{BF}$ & $\begin{array}{l}-- \\
--\end{array}$ & $\begin{array}{l}0.6466 \\
(0.163)\end{array}$ & $\begin{array}{l}2.0518 \\
(0.986)\end{array}$ & $\begin{array}{l}-- \\
--\end{array}$ & $\begin{array}{l}15.0756 \\
(12.057)\end{array}$ & $\begin{array}{l}36.9397 \\
(22.649)\end{array}$ \\
\hline GEF & $\begin{array}{l}-- \\
--\end{array}$ & $\begin{array}{l}0.7421 \\
(0.197)\end{array}$ & $\begin{array}{l}1.6625 \\
(0.952)\end{array}$ & $\begin{array}{l}-- \\
--\end{array}$ & $\begin{array}{l}32.112 \\
(17.397)\end{array}$ & $\begin{array}{l}13.2688 \\
(9.967)\end{array}$ \\
\hline MOF & $\begin{array}{l}0.4816 \\
(0.252)\end{array}$ & $\begin{array}{l}2.3876 \\
(0.253)\end{array}$ & $\begin{array}{l}1.5441 \\
(0.226)\end{array}$ & $\begin{array}{l}-- \\
--\end{array}$ & $\begin{array}{l}-- \\
--\end{array}$ & $\begin{array}{l}-- \\
--\end{array}$ \\
\hline $\mathrm{TF}$ & $\begin{array}{l}-- \\
--\end{array}$ & $\begin{array}{l}2.7898 \\
(0.165)\end{array}$ & $\begin{array}{l}1.3068 \\
(0.034)\end{array}$ & $\begin{array}{c}0.1298 \\
(0.208)\end{array}$ & $\begin{array}{l}-- \\
--\end{array}$ & $\begin{array}{l}-- \\
--\end{array}$ \\
\hline F & $\begin{array}{l}-- \\
--\end{array}$ & $\begin{array}{l}2.8876 \\
(0.234)\end{array}$ & $\begin{array}{l}1.2643 \\
(0.059)\end{array}$ & $\begin{array}{l}- \\
--\end{array}$ & $\begin{array}{l}-- \\
--\end{array}$ & $\begin{array}{l}-- \\
--\end{array}$ \\
\hline
\end{tabular}

the Mathcad program. Based on these criteria in Table 2 and 4 , we conclude that the Kw-TMOF distribution provides $0 \mathrm{a}$ superior fit to these data than its sub models and non-nested models. Figure 3 and 4 display the fitted pdf and cdf the Kw-TMOF model to both data sets. It is clear from these plots that the $\mathrm{Kw}$-TMOF provides close fit to the two data sets. 
Table 4: The statistics and for data set 2

\begin{tabular}{lccccc}
\hline Models & $-\hat{2 \rho}$ & AIC & BIC & HQIC & CAIC \\
\hline Kw-TMOF & 291.292 & 303.292 & 318.923 & 309.168 & 304.195 \\
KTMOIE & 301.016 & 311.016 & 324.022 & 316.288 & 311.645 \\
BF & 303.133 & 311.133 & 321.553 & 315.350 & 31.554 \\
GEF & 303.960 & 311.960 & 332.381 & 316.178 & 312.381 \\
TMOF & 301.973 & 309.973 & 320.393 & 314.190 & 310.394 \\
MOF & 345.328 & 351.328 & 359.143 & 354.491 & 351.578 \\
TF & 344.475 & 350.475 & 358.290 & 353.638 & 350.725 \\
F & 344.308 & 348.308 & 353.519 & 350.417 & 348.432 \\
\hline
\end{tabular}

Table 5: MLEs and their standard errors (in parentheses) for data set 2

\begin{tabular}{|c|c|c|c|c|c|c|}
\hline \multirow[b]{2}{*}{ Models } & \multicolumn{6}{|l|}{ Estimates } \\
\hline & $\hat{\alpha}$ & $\hat{\beta}$ & $\hat{\theta}$ & $\hat{\lambda}$ & $\hat{a}$ & $\hat{b}$ \\
\hline Kw-TMOF & $\begin{array}{l}1.0766 \\
(0.53)\end{array}$ & $\begin{array}{l}0.5893 \\
(0.088)\end{array}$ & $\begin{array}{l}4.5252 \\
(5.293)\end{array}$ & $\begin{array}{l}-5.5611 \times 10^{5} \\
(0.509)\end{array}$ & $\begin{array}{l}3.0559 \\
(1.669)\end{array}$ & $\begin{array}{l}67.2623 \\
(46.922)\end{array}$ \\
\hline KTMOIE & $\begin{array}{l}1.4565 \\
(0.416)\end{array}$ & $\begin{array}{l}-- \\
--\end{array}$ & $\begin{array}{l}2.9071 \\
(1.967)\end{array}$ & $\begin{array}{l}-0.0002 \\
(0.336)\end{array}$ & $\begin{array}{l}1.7674 \\
(0.892)\end{array}$ & $\begin{array}{l}9.6266 \\
(2.585)\end{array}$ \\
\hline $\mathrm{BF}$ & $\begin{array}{l}-- \\
--\end{array}$ & $\begin{array}{l}0.4046 \\
(0.108)\end{array}$ & $\begin{array}{l}1.6097 \\
(2.498)\end{array}$ & $\begin{array}{l}-- \\
--\end{array}$ & $\begin{array}{l}22.0143 \\
(21.432)\end{array}$ & $\begin{array}{l}29.7617 \\
(17.479)\end{array}$ \\
\hline GEF & $\begin{array}{l}-- \\
--\end{array}$ & $\begin{array}{l}0.4776 \\
(0.133)\end{array}$ & $\begin{array}{l}1.3692 \\
(2.017)\end{array}$ & $\begin{array}{l}-- \\
--\end{array}$ & $\begin{array}{l}27.6452 \\
(14.136)\end{array}$ & $\begin{array}{l}17.4581 \\
(14.818)\end{array}$ \\
\hline TMOF & $\begin{array}{l}101.923 \\
(47.625)\end{array}$ & $\begin{array}{l}3.3313 \\
(0.206)\end{array}$ & $\begin{array}{l}0.6496 \\
(0.068)\end{array}$ & $\begin{array}{l}0.2936 \\
(0.27)\end{array}$ & $\begin{array}{l}-- \\
--\end{array}$ & $\begin{array}{l}-- \\
--\end{array}$ \\
\hline MOF & $\begin{array}{l}0.5988 \\
(0.3091)\end{array}$ & $\begin{array}{l}1.5796 \\
(0.16)\end{array}$ & $\begin{array}{l}2.3066 \\
(0.498)\end{array}$ & $\begin{array}{l}-- \\
--\end{array}$ & $\begin{array}{l}-- \\
--\end{array}$ & $\begin{array}{l}-- \\
--\end{array}$ \\
\hline $\mathrm{TF}$ & $\begin{array}{l}-- \\
--\end{array}$ & $\begin{array}{l}1.7435 \\
(0.076)\end{array}$ & $\begin{array}{l}1.9315 \\
(0.097)\end{array}$ & $\begin{array}{l}0.0819 \\
(0.198)\end{array}$ & $\begin{array}{l}-- \\
--\end{array}$ & $\begin{array}{l}-- \\
--\end{array}$ \\
\hline $\mathrm{F}$ & $\begin{array}{l}-- \\
--\end{array}$ & $\begin{array}{l}1.7766 \\
(0.113)\end{array}$ & $\begin{array}{l}1.8705 \\
(0.112)\end{array}$ & $\begin{array}{l}-- \\
--\end{array}$ & $\begin{array}{l}-- \\
--\end{array}$ & $\begin{array}{l}-- \\
--\end{array}$ \\
\hline
\end{tabular}

\section{CONCLUSION}

In this study, we propose a new six-parameter distribution, called the Kumaraswamy transmuted Marshall-Olkin Frechet (Kw-TMOF) distribution which extends the transmuted Marshall-Olkin Frechet (TMOF) distribution (Afify et al., 2014a, b). We provide some of its mathematical and statistical properties. The Kw-TMOF density function can be expressed as a mixture of Frechet densities. We derive explicit expressions for the ordinary and incomplete moments, Renyi and $\eta$-entropies. We also obtain the density function of the order statistics and their moments. We discuss maximum likelihood estimation and calculate the information matrix. Two applications illustrate that the $\mathrm{Kw}$-TMOF distribution provides better fit than other competitive distributions. We hope that the proposed extended model may attract wider applications in survival analysis.

\section{REFERENCES}

Afify, A.Z., G. Hamedani, I. Ghosh and M.E. Mead, 2014a. The transmuted Marshall-Olkin frechet distribution: Properties and applications. Intl. J. Stat. Probab., 4: 132-148.
Afify, A.Z., H.M. Yousof, G.M. Cordeiro, E.M.M. Ortega and Z.M. Nofal, 2016a. The Weibull Frechet distribution and its applications. J. Appl. Stat., 43: 2608-2626.

Afify, A.Z., H.M. Yousof, G.M. Cordeiro, Z.M. Nofal and M. Ahmad, 2016b. The kumaraswamy marshall-olkin frechet distribution with applications. J. ISOSS., 2: $151-168$.

Afify, A.Z., Z.M. Nofal and N.S. Butt, 2014b. Transmuted complementary Weibull geometric distribution. Pak. J. Stat. Operation Res., 10: 435-454.

Ahmad, A., S.P. Ahmad and A. Ahmed, 2014. Transmuted Inverse Rayleigh distribution: A generalization of the Inverse Rayleigh distribution. Math. Theory Mod., 4: 90-98.

Barlow, R.E. and F. Proschan, 1996. Mathematical Theory of Reliability. SIAM Publisher, USA., ISBN:978-0-89871-369-5, Pages: 257.

Barreto-Souza, W., G.M. Cordeiro and A.B. Simas, 2011. Some results for beta Frechet distribution. Commun. Stat. Theor. Methods, 40: 798-811.

Cordeiro, G.M. and M. de Castro, 2011. A new family of generalized distributions. J. Stat. Comput. Simul., 81: 883-898.

Da Silva, R.V., T.A.N. De Andrade, D.B.M. Maciel, R.P.S. Campos and G.M. Cordeiro, 2013. A new lifetime model: The gamma extended Frechet distribution. J. Stat. Theor. Appl., 12: 39-54. 
De Gusmao, F.R.S., E.M. Ortega and G.M. Cordeiro, 2011. The generalized inverse Weibull distribution. Stat. Pap., 52: 591-619.

Elbatal, I., G. Asha and A.V. Raja, 2014. Transmuted exponentiated Frechet distribution: Properties and applications. J. Stat. Appl. Probab., 3: 379-394.

Frechet, M., 1924. [On the law of observation errors (In French)]. Math. Collect., 32: 5-8.

Glanzel, W., 1987. A Characterization Theorem Based on Truncated Moments and its Application to Some Distribution Families. In: Mathematical Statistics and Probability Theory, Bauer, P., F. Konecny and W. Wertz (Eds.). Springer, Dordrecht, Netherlands, ISBN:978-94-010-8259-4, pp: 75-84.

Glanzel, W., 1990. Some consequences of a characterization theorem based on truncated moments. Stat., 21: 613-618.

Keller, A.Z., A.R.R. Kamath and U.D. Perera, 1982. Reliability analysis of CNC machine tools. Reliabil. Eng., 3: 449-473.

Kotz, S. and S. Nadarajah, 2000. Extreme Value Distributions: Theory and Applications. Imperial College Press, London, UK.

Krishna, E., K.K. Jose, T. Alice and M.M. Ristic, 2013. The Marshall-Olkin Frechet distribution. Commun. Stat. Theor. Methods, 42: 4091-4107.

Mahmoud, M.R. and R.M. Mandouh, 2013. On the transmuted Frechet distribution. J. Appl. Sci. Res., 9: 5553-5561.
Mead, M.E., A.Z. Afify, G.G. Hamedani and I. Ghosh, 2017. The beta exponential Frechet distribution with applications. Austrian J. Stat., 46: 41-63.

Mead, M.E.A., 2014. A note on Kumaraswamy Frechet distribution. Aust., 8: 294-300.

Merovci, F., I. Elbatal and A. Ahmed, 2013. Transmuted generalized inverse Weibull distribution. Methodology, 1: 1-16.

Nadarajah, S. and A.K. Gupta, 2004. The beta Frechet distribution. Far East J. Theor. Stat., 14: 15-24.

Nichols, M.D. and W.J. Padgett, 2006. A bootstrap control chart for Weibull percentiles. Quality Reliabil. Eng. Int., 22: 141-151.

Oguntunde, P.E. and O. Adejumo, 2015. The transmuted inverse exponential distribution. Int. J. Adv. Stat. Probabil., 3: 1-7.

Shahbaz, M.Q., S. Shahbaz and N.S. Butt, 2012. The kumaraswamy-inverse weibull distribution. Pak. J. Stat. Oper. Res., 8: 479-489.

Smith, R.L. and J.C. Naylor, 1987. A comparison of maximum likelihood and Bayesian estimators for the three-parameter Weibull distribution. J. R. Stat. Soc. Ser. C. Appl. Stat., 36: 358-369.

Treyer, V.N., 1964. Doklady Acad. Nauk Publisher, Minsk, Belarus,

Yousof, H.M., A.Z. Afify, M. Alizadeh, N.S. Butt and G. Hamedani, 2015. The transmuted exponentiated generalized-G family of distributions. Pak. J. Stat. Oper. Res., 11: 441-464. 